\title{
NOTA SOBRE ALGUNAS APORTACIONES RECIENTES DE LA HISTORIOGRAFIA PORTUGUESA
}

\author{
ELOY FEŔNANDEZ CLEMENTE \\ Universidad de Zaragoza
}

Cuando en el número 3 -otoño de 1988- de esta Revista nos ocupábamos de informar sobre la Historia Económica de Portugal (siglos XIX y $\mathrm{xx}$ ), repasando una rica producción bibliográfica, producto de una profunda renovación de esos trabajos en las últimas dos o tres décadas, nos prometimos continuar ese servicio al creciente número de estudiosos interesados en los asuntos de nuestro vecino país.

Ahora, a la vez que realizamos, en la sección correspondiente, una recensión de una edición importante sobre una de las máximas figuras del siglo XIX portugués (Mouzinho da Silveira), creemos es buen momento para, en una breve Nota, mencionar algunas novedades que hemos ido conociendo en estos dos años escasos.

Citemos en primer lugar $A$ formação do espacio económico nacional. Portugal, 1810-1913, de David Justino, que resumíamos antes de ser editada (dos volúmenes, Vega, Lisboa, 1988). Una obra sobre la que habríamos de voiver alguna vez, por lo rico y novedoso de sus propuestas y análisis. Otra novedad que, en cierto modo, la complementa y sintetiza con rigor, para lectores de Europa central y del norte, es Le Portugal au XXe. siècle, 1910 1985, de Jacques Mercadé (PUF, París, 1988).

Sobre la larga etapa de la Dictadura, han aparecido el tomo II de O Estado novo. Das Origens ao fim da Autarcia, 1926-1959 (fechado en Lisboa, 1987), obra colectiva en la que destacaríamos los bloques sobre la cuestión colonial, enseñanza y urbanismo, y el estudio de Fátima Nunes sobre «Revista de Economia» (1948-1958); el breve libro de Douglas Wheeler, A Ditadura Militar portuguesa (1926-1933) (Europa-América, Lisboa, 1986); y la importante tesis de Manuel Braga da Cruz $O$ partido e o estado no Salazarismo (Presença, Lisboa, 1988).

Añadamos algunos libros colectivos, como Arquivo e Historiografia, actas del Coloquio sobre Fuentes de la Historia Contemporánea Portuguesa, que coordinan M. J. da .Silva Leal y M. Halpern Pereira (Imprensa Nacional, Lisboa, 1988); Contribuições para a História do pensamento económico em 
Portugal, actas del Seminario organizado por el CISEP en 1987), coordinado por J. L. Cardoso (Dom Quixote, Lisboa, 1988); y el volumen de Estudos $e$ ensaios. Em Homenagem a Vitorino Malgabães Godinbo (Sá da Costa, Lisboa, 1988).

Este título nos merece párrafo aparte, por tratarse de la salutación jubilar a uno de los jefes de fila de la Historia Económica de Portugal, impulsor de numerosos estudios, director de tesis muy celebradas y de la fraterna Revista de História Económica e Social, amén de varias veces ministro en los albores de la revolución democrática, director de la Biblioteca Nacional, etcétera. En el grueso y denso volumen, además de autoridades del prestigio de F. Mauro, A. Tenenti, A. Silbert, I. Wallerstein L. de Alburquerque o J. Mattoso, se presentan trabajos sobre el tema más querido al profesor Godinho (los descubrimientos) y aportan estudios sobre muy distintas épocas y asuntos un puñado de discípulos del homenajeado.

Por último, en esta apretada y selectiva nota, recordemos que el estudio de las relaciones Portugal-España ha seguido acrecentándose. De aquel lado de la raya, con libros como los de A. P. Manique, Portugal e as potências europeias (1807-1847) (Horizonte, Lisboa, 1988); P. Penner da Cunha, Sob fogo. Portugal e Espanba entre 1800 e 1820 (Horizonte, Lisboa, 1988); J. Medeiros Ferreira, Um século de Problemas. As relações luso-espanbolas da união Ibérica à Comunidade Europeia (Horizonte, Lisboa, 1989); o el ya célebre ensayo de Natalia Correia, Somos todos hispanos (O Jornal, Lisboa, 1988).

Del nuestro, por la continuación de los trabajos de dos de nuestros principales lusistas: Pilar Vázquez Cuesta, cuya aportación a la Historia de España de Menéndez Pidal (vol. XVI-II, 1986) se edita allí como $A$ lengua $e$ a Cultura Portuguesas no tempo dos Felipes (Europa-América, Lisboa, 1988); e Hipólito de la Torre, que coordina el número 8 (abril de 1989) monográfico de la revista Proserpina, de la UNED de Extremadura, que recoge las ponencias y debates del Seminario celebrado en Mérida el pasado año sobre España, Portugal y la OTAN.

Otra publicación colectiva, el número 21 (abril de 1988) de República de las Letras (editada por la Asociación Colegial de Escritores de España), sobre Portugal y España: dos sociedades, dos transiciones, dos literaturas. $\mathrm{Y}$, no desde luego en último lugar, el denso estudio de J. Ignacio Lacasta Zabalza, Cultura y Gramática del Leviatán Portugués (Prensas Universitarias de Zaragoza, 1988), intrépida y feliz indagación sobre los procesos constitucionales de ambos países desde 1974 y 1975. 